\title{
Zur Problematik des Beteiligungsquorums
}

\section{Otmar Jung}

\section{A. Die Relevanz des Themas}

\section{Quoren im Allgemeinen}

Die Regelwerke der direkten Demokratie in Deutschland kennen Quoren als zusätzliche Bedingungen, die erfüllt sein müssen, damit ein Volksentscheid, bei dem eine Vorlage an den Urnen eine Mehrheit gefunden hat, ${ }^{1}$ als gültig anerkannt wird. Solche Zusatzbedingungen gibt es im Wesentlichen in zwei Formen: Beim sogenannten Zustimmungsquorum muß die erreichte Mehrheit an den Urnen zugleich einen bestimmten Prozentsatz der Gesamtheit der Stimmberechtigten ausmachen. Beim sogenannten Beteiligungsquorum hingegen gilt die an den Urnen getroffene Annahmeentscheidung nur dann, wenn sich ein bestimmter Prozentsatz der Stimmberechtigten insgesamt an der Abstimmung beteiligt hat.

In den großen Referenzländern für direkte Demokratie - der Schweiz auf allen politischen Ebenen und den US-Bundesstaaten - sind solche Quoren unbekannt; einige deutsche Landes- und Kommunalverfassungen sind ihnen gefolgt. ${ }^{2}$ Dort entscheidet lediglich die Mehrheit derer, die bei einer Abstimmung zu den Urnen kommen und ihren Willen durch Ja oder Nein kundtun. Hingegen kennt z. B. auch Italien solche Zusatzbedingungen.

Beide Quorenformen sind als Durchbrechungen des erzdemokratischen Prinzips - das etwa im Wahlrecht selbstverständlich gilt -, daß die Mehrheit der Aktivbürger entscheidet und Unentschlossene, Desinteressierte, Verhinderte und sonstige Nichtabstimmende für den Fortgang des Entscheidungsprozesses außer Betracht bleiben, rechtfertigungsbedürftig und müssen in ihren Auswirkungen auf das Stimmverhalten problematisiert werden. ${ }^{3}$ Dieser Beitrag konzentriert sich dabei auf das Beteiligungsquorum. Seine Probleme hat zuletzt $P$. Neumann unter Beiziehung von viel Literatur erörtert. ${ }^{4}$

1 Nur diese Konstellation führt zu dem hier interessierenden Problem. Wenn eine Vorlage an den Urnen mehrheitlich abgelehnt wurde, stellt sich die Quorenfrage nicht mehr.

2 Eine quorenlose Abstimmung kennen Bayern (vgl. Art. 74 i.V.m. Art. 2 Abs. 2 S. 2 Verf.), Hessen (Art. 124 Abs. 3 S. 2 Verf.) und Sachsen (Art. 72 Abs. 4 S. 2 Verf.) für Volksentscheide über einfachgesetzliche Vorlagen, ferner Hamburg beim Bürgerentscheid auf Bezirksebene $(\S 8 \mathrm{a}$ Abs. 9 S. 2 BezVG).

3 Vgl. F. Wittreck, Direkte Demokratie und Verfassungsgerichtsbarkeit. Eine kritische Übersicht zur deutschen Verfassungsrechtsprechung in Fragen der unmittelbaren Demokratie von 2000 bis 2002, JöR 53 (2005), 111 (180f.).

4 Vgl. P. Neumann, Sachunmittelbare Demokratie im Bundes- und Landesverfassungsrecht unter besonderer Berücksichtigung der neuen Länder, 2009, S. 379-389. 


\section{Konkrete Regelungen des Beteiligungsquorums}

$\mathrm{Zu}$ Beginn des letzten Viertels des vorigen Jahrhunderts stand das Beteiligungsquorum in Deutschland auf dem Aussterbeetat. 21 Jahre lang - von November 1974 bis November 1995 - kannte lediglich noch Bremen diese Zusatzbedingung (Art. 72 Abs. 1 Verf. a.F.: ,wenn sich die Mehrheit der Stimmberechtigten an der Abstimmung beteiligt"), und auch die Hansestadt stellte 1997 von einem 50prozentigen Beteiligungs- auf ein 25prozentiges Zustimmungsquorum um. ${ }^{5}$ Doch inzwischen hatte Berlin mit seiner neuen Verfassung von 1995 zugleich die alte „Berliner Doppelhürde“, die ein Beteiligungsquorum einschloß, wieder aufgerichtet (Art. 63 Abs. 2 Verf. ${ }^{6}$ ), so daß es in der Zeit nach dem Zweiten Weltkrieg nie eine Phase ohne jenes Instrument gab. Seitdem ist sogar eine kleine Renaissance zu verzeichnen. Seit 2000 gilt in Rheinland-Pfalz, daß zwar grundsätzlich die Mehrheit der abgegebenen gültigen Stimmen über Annahme oder Ablehnung eines volksbegehrten Gesetzentwurfs entscheidet; ,ein Gesetz kann jedoch nur beschlossen ... werden, wenn sich mindestens ein Viertel der Stimmberechtigten an der Abstimmung beteiligt" (Art. 109 Abs. 4 S. 3 Halbs. 2 Verf. $^{7}$ ). Und Nordrhein-Westfalen bestimmte 2002 für die verfassungsändernde Volksgesetzgebung, daß ein Gesetzentwurf nur angenommen ist, ,wenn mindestens die Hälfte der Stimmberechtigten sich an dem Volksentscheid beteiligt", wobei mindestens zwei Drittel der Abstimmenden dem Gesetzentwurf zustimmen müssen (Art. 69 Abs. 3 S. 3 Verf. ${ }^{8}$ ). Im Kommunalverfassungsrecht regelte Berlin 2005, daß eine Vorlage beim Bürgerentscheid angenommen ist, wenn sie eine Mehrheit an den Urnen gefunden hat und sich mindestens

5 Vgl. Art. 1 Nr. 6 a) Gesetz zur Änderung der Landesverfassung der Freien Hansestadt Bremen v. 9.10.1997, GB1. S. 353. Siehe Art. 72 Abs. 1 Verf. n.F.: ,wenn die Mehrheit derjenigen, die ihre Stimme abgegeben haben, jedoch mindestens ein Viertel der Stimmberechtigten, zugestimmt hat". - Irrig auf 1994 datiert diese Umstellung A. Fisahn, Direkte Demokratie in Bremen, in: A. Kost (Hrsg.), Direkte Demokratie in den deutschen Ländern. Eine Einführung, 2005, S. 98 (105 Fn. 13); ihm folgen C. Eder/R. Magin, Direkte Demokratie, in: M. Freitag/A. Vatter (Hrsg.), Die Demokratien der deutschen Bundesländer. Politische Institutionen im Vergleich, 2008, S. 257 (281).

6 Verfassung von Berlin v. 23.11.1995, GVB1. S. 779. - Diese spezielle Hürde, auf die noch einzugehen ist - bei 50 Prozent Beteiligung genügte die einfache Mehrheit, bei geringerer Beteiligung war die Zustimmung von 33 Prozent der Stimmberechtigten erforderlich -, galt schon von 1950 bis 1974 (Art. 49 Abs. 4 Verf.), in welchem Jahr sie mit der Amputation der Verfassung um die Volksgesetzgebung insgesamt mit entfiel.

7 Vgl. Art. 1 Nr. 27 b) Vierunddreißigstes Landesgesetz zur Änderung der Verfassung für Rheinland-Pfalz v. 8.3.2000, GVB1. S. 65. - Dies war für sich genommen eine Erschwerung gegenüber dem bis dahin geltenden quorenlosen Volksentscheid nach Art. 109 Abs. 4 S. 2 Verf. a.F. Jedoch ist zu bedenken, daß es um eine Reform der direkten Demokratie in Rheinland-Pfalz insgesamt ging, so daß für ein Gesamturteil vor allem auch die Halbierung der Hürde beim Volksbegehren von 20 auf (umgerechnet) 10 Prozent mit abzuwägen ist.

8 Vgl. Art. I Nr. 3 Gesetz zur Änderung der Verfassung für das Land Nordrhein-Westfalen v. 5.3.2002, GVB1. S. 108. - Dies ist vor dem Hintergrund zu würdigen, daß bis dahin die herrschende Meinung - zu Unrecht (vgl. O. Jung, Volksbegehren auf Verfassungsänderung in Hessen und Nordrhein-Westfalen? KritV 76 [1993], 14 [27-33]) - die Zulässigkeit verfassungsändernder Volksgesetzgebung überhaupt bestritt. Diese wurde nun klargestellt, u.a. um jenen Preis. 
15 Prozent der Stimmberechtigten beteiligt haben ( $\$ 47$ Abs. 1 Satz 1 BezVG). Aber auf der Landesebene gab Berlin im folgenden Jahr endlich der „Berliner Doppelhürde“ den Abschied. Seit 2006 gilt beim Volksentscheid in Berlin ein „normales“ 25prozentiges Zustimmungsquorum (Art. 63 Abs. 1 Satz 3 Verf.). ${ }^{9}$

Im Bereich der Verfassungspolitik auf Bundesebene feierte das Beteiligungsquorum unter Rot-Grün nachgerade fröhlich Urständ. Die Ad-hoc-Arbeitsgruppe Beteiligungsrechte beim Parteivorstand der SPD sah in ihrem Bericht vom 19. Februar 2001 noch Beteiligungsquoren von 20 bzw. 50, ja 66 Prozent für einfache Gesetzentwürfe vor und von $40 \mathrm{bzw}$. 66 Prozent für verfassungsändernde Vorlagen. In dem vom Parteivorstand einen Monat später verabschiedeten sogenannten Eckpunktepapier rang sich die SPD dazu durch, die jeweils untersten der erwogenen Beteiligungsquoren ( $20 \mathrm{bzw}$. 40 Prozent) anzusetzen, ${ }^{10}$ was immer noch deutliche Kritik erforderte. ${ }^{11}$ Diese Beteiligungsquoren setzte die SPD auch in dem gemeinsamen rot-grünen Entwurf vom 13. März 2002 durch, ${ }^{12}$ der dann am 7. Juni 2002 eine zwar nur einfache, aber immerhin eine - Mehrheit im Deutschen Bundestag fand. In Hessen endlich brachte die Fraktion Bündnis 90/Die Grünen 2008 einen Gesetzentwurf im Landtag ein, der die von der herrschenden Meinung - unrichtigerweise ${ }^{13}$ - bestrittene Zulässigkeit verfassungsändernder Volksgesetzgebung klarstellen sollte. Danach sollte - bei fehlender Zustimmung des Landtags - der bejahende Volksentscheid über einen volksbegehrten Entwurf einer Verfassungsänderung nur dann gültig sein, wenn ,sich mindestens die Hälfte der Stimmberechtigten hieran beteiligt" hätte. ${ }^{14}$

Rechtshistorisch sei vor allem an Art. 76 WRV erinnert. Danach konnte durch den Volksentscheid ,ein Beschluß des Reichstags nur dann außer Kraft gesetzt werden, wenn sich die Mehrheit der Stimmberechtigten an der Abstimmung beteiligt“".

9 Achtes Gesetz zur Änderung der Verfassung von Berlin v. 25.5.2006, GVB1. S. 446. Die Änderung trat laut Art. II Abs. 1 und 2 S. 2 dieses Gesetzes i.V.m. der Bek. über das Ergebnis der Volksabstimmung am 17. September 2006 über die Neuregelung von Volksbegehren und Volksentscheid in der Verfassung von Berlin v. 12.10.2006, GVBl. S. 1002, mit Beginn der 16. Wahlperiode des Abgeordnetenhauses von Berlin in Kraft. Diese Wahlperiode begann mit dem ersten Zusammentritt des am 17. September 2006 neu gewählten Abgeordnetenhauses (vgl. Art. 54 Abs. 1 S. 2 Verf.); dies war der 26. Oktober 2006. - Es irritiert etwas, daß Eder/ Magin, Direkte Demokratie (Fn. 5), die Reform von 2006 zwar wahrnehmen (S. 267), ihre Tabellen auf dem Stand von 2005 aber nicht aktualisieren und weiterhin mit der abgeschafften Doppelhürde operieren (S. 281, ebenso dies., Volksgesetzgebung in den deutschen Bundesländern: ein Vorschlag zu ihrer empirischen Erfassung aus subnational-vergleichender Perspektive, in: ZParl 39 [2008], 358 [371]).

10 Vgl. O. Jung, Volksentscheid ins Grundgesetz? Die politische Auseinandersetzung um ein rotgrünes Reformprojekt 1998-2002, ZfP 49 (2002), 267 (269).

11 Vgl. O. Jung, Eckpunkte nicht überzeugend gesetzt. Wie die SPD die Beteiligungsrechte der Bürger auf Bundesebene ausbauen will, RuP 37 (2001), 61 (66-69).

12 BT-Drs. 14/8503 v. 13.3.2002. Vgl. Jung, Volksentscheid (Fn. 10), 281; siehe ferner H.J. Wiegand, Direktdemokratische Elemente in der deutschen Verfassungsgeschichte, 2006, S. 292-295.

13 Vgl. Jung, Verfassungsänderung (Fn. 8), 14-27.

14 Vgl. Gesetz zur Änderung der Verfassung des Landes Hessen (Verfassungsänderung durch Volksbegehren und Volksentscheid), HessLT Drs. 17/481 v. 13.8.2008. 
Auch auf Landesebene war ein Beteiligungsquorum die häufigste Zusatzbedingung, welche die Verfassungen der Weimarer Zeit bei Volksentscheiden über einfachgesetzliche Vorlagen aufstellten: in der Regel betrug es 50 Prozent der Stimmberechtigten, in Bayern hingegen nur 20 Prozent. Für verfassungsändernde Gesetzentwürfe galt im allgemeinen ein Zustimmungsquorum von 50 Prozent; nur Bayern blieb bei einem (verdoppelten) Beteiligungsquorum von 40 Prozent. Vor der plebiszitären Parlamentsauflösung, die unter den hier interessierenden Gesichtspunkten ebenso interessant ist wie die Sachentscheide, waren regelmäßig ähnlich hohe Hürden aufgerichtet wie vor Verfassungsänderungen, aber einige Verfassungen beließen es auch in diesem Fall bei einem Beteiligungsquorum. ${ }^{15}$

Komparatistisch ist auf Italien hinzuweisen, wo das sogenannte Abrogative Referendum nur wirksam ist, wenn sich die Mehrheit der Stimmberechtigten an der Abstimmung beteiligt und wenn sich die Mehrheit der abgegebenen gültigen Stimmen für die Aufhebung des umstrittenen Gesetzes ausspricht (Art. 75 Abs. 4 Verf.). ${ }^{16}$

\section{B. Die Versuchung zum Boykott}

I. Fälle

\section{Zur Weimarer Zeit}

\section{a) Reichsebene}

Beim ersten reichsweiten Volksentscheid in Deutschland zur „Fürstenenteignung“ am 20. Juni 1926 gaben die Sachgegner von der Rechten die Parole aus „Bleibt zu Hause!" und organisierten, wo immer ihnen das möglich war, den Boykott im ruppigen Politikstil der Zeit: aufreizende Zeitungsschlagzeilen („Heute Bolschewistenzählung"), Überwachung der Abstimmungslokale durch Posten, die jeden, der sich am Volksentscheid beteiligte, aufschrieben, und Androhung der Entlassung für Arbeiter, die zur Abstimmung gingen, was in Ostelbien auch wahrgemacht wurde. ${ }^{17}$ Im Ergebnis scheiterte der Volksentscheid „mangels Beteiligung“18 - worunter man sich allerdings nichts Falsches vorstellen darf: 1926 strömten 15,6 Millionen Bür-

15 Vgl. die Übersicht bei F. Wittreck (Hrsg.), Weimarer Landesverfassungen. Die Verfassungsurkunden der deutschen Freistaaten 1918-1933, 2004, S. 46-50. - Heute kennen Beteiligungsquoren für den Fall plebiszitärer Parlamentsauflösung noch die Verfassungen von Berlin (Art. 63 Abs. 3 S. 3 - 50\%) und Rheinland-Pfalz (Art. 109 Abs. 4 S. 3 Halbs. 2 - 25\%).

16 Vgl. A. Capretti, Direkte Demokratie in Italien, in: H.K. Heußner/O. Jung (Hrsg.), Mehr direkte Demokratie wagen. Volksentscheid und Bürgerentscheid: Geschichte - Praxis - Vorschläge, 2. Aufl. 2009, S. 157 (161 f.).

17 Vgl. für einzelne Fälle O. Jung, Volksgesetzgebung. Die „Weimarer Erfahrungen“ aus dem Fall der Vermögensauseinandersetzungen zwischen Freistaaten und ehemaligen Fürsten, 2. Aufl. 1996, S. 968-986.

18 Vgl. das Faksimile der Bek. v. 24.1.1928 über das Ergebnis des Volksentscheids „Enteignung der Fürstenvermögen“, bei O. Jung, Direkte Demokratie in der Weimarer Republik. Die Fälle „Aufwertung“, „Fürstenenteignung“, „Panzerkreuzerverbot“" und „Youngplan“, 1989, S. 62. 
gerinnen und Bürger zu den Abstimmungslokalen. Hätte eine Partei oder Parteienkoalition bei Reichstagswahlen so viele Stimmen auf sich vereinigt, wie damals für eine „Fürstenenteignung“ votierten, hätte sie die absolute Mehrheit der Mandate erhalten..$^{19}$ Aber es lauteten eben nur 3,9 Prozent der abgegebenen gültigen Stimmen auf „Nein“, d.h. die Sachgegner waren offensichtlich gar nicht ,angetreten“.

Dreieinhalb Jahre später kehrte die Linke den Spieß um. Der Volksentscheid gegen den Youngplan am 22. Dezember 1929 wurde genau mit den gleichen Mitteln boykottiert und sabotiert, die 1926 die Rechte eingesetzt hatte. 5,8 Millionen Bürgerinnen und Bürger stimmten für den vorgeschlagenen Gesetzentwurf, aber nur 338.258 (gleich 5,5 Prozent) dagegen. ${ }^{20}$ Wiederum hatte der Boykott gegriffen. Dieser zweite und letzte reichsweite Volksentscheid der Weimarer Zeit war ebenfalls am Beteiligungsquorum gescheitert. ${ }^{21}$

\section{b) Landesebene}

Die Staatspraxis auf der Landesebene weist fünf Volksentscheide aus, die unter einem Beteiligungsquorum ausgetragen wurden: zwei Sachentscheidungen, nämlich den Volksentscheid in Bayern am 6. April/4. Mai 1924 über die Neuwahl eines verfassunggebenden Landtags ${ }^{22}$ und den Volksentscheid in Lippe am 2. Dezember 1928 über die Änderung des Tierzuchtgesetzes, ${ }^{23}$ sowie drei Volksentscheide zur

191926 stimmten knapp 14,5 Millionen Bürger für den Gesetzentwurf; bei Reichstagswahlen gab es damals etwa 30 Millionen Aktivbürger.

20 Vgl. das Faksimile der Bek. v. 15.3.1930 über das Ergebnis des Zweiten Volksentscheids, bei Jung, Weimarer Republik (Fn. 18), S. 140.

21 Vgl. O. Jung, Historische Erfahrungen mit direkt-demokratischen Elementen in der deutschen (Verfassungs-)Geschichte, in: Demokratie lebendiger gestalten. Ettersburger Gespräche am 10. und 11. November 2000 im Hotel Amalienhof Weimar, hrsg. vom Thüringer Landtag, 2001, S. 11 (24, 38); dort (S. 24) auch schon Argumente gegen die jüngst von Gusy erneut vorgetragene Einschätzung, die volksbegehrten Gesetzentwürfe zur Fürstenenteignung und zum Young-Plan seien beim Volksentscheid ,abgelehnt“ worden, was ,geradezu als Zeugnis demokratischer Reife der Bürger angesehen werden“ müsse: C. Gusy, Eine gute Verfassung mit schlechtem Image: Die Weimarer Reichsverfassung, RuP 2009, 74 (76). Den durch Ausgabe der Boykottparole und Einsatz von Sozialdruck zwangsläufig verzerrten Abstimmungsergebnissen kommt eine entsprechende Aussagekraft („Reife“) keineswegs zu. Die „Weimarer Erfahrungen" beschränken sich insofern darauf, daß man eine Verfahrensordnung vermeiden sollte, die solche undemokratischen Mittel wie Boykott und Einsatz von Sozialdruck überhaupt ermöglicht. - Ferner C. Schwieger, Volksgesetzgebung in Deutschland. Der wissenschaftliche Umgang mit plebiszitärer Gesetzgebung auf Reichs- und Bundesebene in Weimarer Republik, Drittem Reich und Bundesrepublik Deutschland (1919-2002), 2005, S. 127-133.

22 Dabei galt nach $\S 10$ Abs. 3 Satz 2 Verf. ein 40prozentiges Beteiligungsquorum.

23 Dabei galt nach Art. 4 Abs. 2 Verf. ein 50prozentiges Beteiligungsquorum. - Diesen Volksentscheid übersieht Wittreck, Weimarer Landesverfassungen (Fn. 15), S. 307. 
Landtagsauflösung, nämlich in Schaumburg-Lippe ${ }^{24}$ am 24. August 1924, in Lippe $^{25}$ am 26. April 1931 und in Sachsen ${ }^{26}$ am 17. April 1932.

Bei allen diesen Volksentscheiden wurde - mit einer Ausnahme, die noch zu erörtern ist - die Boykottparole ausgegeben, die ausweislich der geringen Quote der Nein-Stimmen - 5,1 Prozent in Schaumburg-Lippe, ${ }^{27}$ 11,3 Prozent in Lippe 1928, ${ }^{28} 3,6$ Prozent in Lippe $1931^{29}$ und 3,9 Prozent in Sachsen ${ }^{30}$ - auch ,griff“. Das heißt, die Gegenseite „trat“ einfach nicht ,an“. Ein Staatsrechtslehrer bemerkte im schaumburg-lippischen Fall ironisch-distanziert, daß ,die juristisch richtig informierten Gegner der Auflösung“ eben zu Hause geblieben seien. ${ }^{31}$ Der Boykott ist diesen Prozentsätzen gewissermaßen auf die Stirn geschrieben. ${ }^{32}$

24 Dabei galt nach $\S 4$ Abs. 1, arg. e $\S 11$ Verf. ein 50prozentiges Beteiligungsquorum. J. Rux, Direkte Demokratie in Deutschland. Rechtsgrundlagen und Rechtswirklichkeit der unmittelbaren Demokratie in der Bundesrepublik Deutschland und ihren Ländern, 2008, S. 167, geht irrig von einem 50prozentigen Zustimmungsquorum aus.

25 Dabei galt nach Art. 4 Abs. 2, arg. e Art. 11 Verf. ein 50prozentiges Beteiligungsquorum.

26 Dabei galt nach Art. 36 Abs. 1, 38 Abs. 2 Verf. ein 50prozentiges Beteiligungsquorum. Rux, Direkte Demokratie (Fn. 24), S. 179, nimmt irrig ein 50prozentiges Zustimmungsquorum an.

2730.289 Stimmberechtigte, 12.361 beteiligt, 150 ungültig, $11.593 \mathrm{Ja}, 618 \mathrm{Nein}$, nach: Schaumburg-Lippische Landesanzeigen 1924, S. 305 (Nr. 65 v. 3.9.1924). „Ja“ in Prozent der gültigen Stimmen: 94,9, „Nein“ 5,1; Beteiligung in Prozent der Stimmberechtigten: 40,8 Prozent, Beteiligungsquorum: 50 Prozent; Prozentwerte eigene Berechnung. Die volksbegehrte Landtagsauflösung war damit ,unecht" gescheitert.

28 105.528 Stimmberechtigte, 21.555 abgegebene Stimmen, 173 ungültig, 18.962 Ja, 2.420 Nein, nach: Staatsanzeiger für das Land Lippe 1928, S. 578 (Nr. 97 v. 12.12.1928). „Ja“ in Prozent der gültigen Stimmen: 88,7, „Nein“ 11,3; Beteiligung in Prozent der Stimmberechtigten: 20,4 Prozent, Beteiligungsquorum: 50 Prozent; Prozentwerte eigene Berechnung. Das volksbegehrte Gesetz war damit „unecht“ gescheitert.

29111.039 Stimmberechtigte, 38.089 abgegebene Stimmen, 863 ungültig, 37.226 gültig, 35.882 Ja, 1.344 Nein, nach: Staatsanzeiger für das Land Lippe 1931, S. 177 (Nr. 38 v. 13.5.1931). „Ja“ in Prozent der gültigen Stimmen: 96,4, „Nein“ 3,6; Beteiligung in Prozent der Stimmberechtigten: 34,3 Prozent, Beteiligungsquorum: 50 Prozent; Prozentwerte eigene Berechnung. Die volksbegehrte Landtagsauflösung war damit ,unecht“" gescheitert.

30 3.664.314 Stimmberechtigte, 1.392.401 abgegebene Stimmen, 20.620 ungültig, 1.371 .781 gültig, 1.318.322 Ja, 53.461 Nein: SächsVB1. 1932, S. 365 (mit Begründung, warum die Summe der Ja- und Nein-Stimmen um 2 höher ist als die Zahl der gültigen Stimmen). ,Ja“ in Prozent der gültigen Stimmen: 96,1, „Nein“ 3,9; Beteiligung in Prozent der Stimmberechtigten: 38,0 Prozent, Beteiligungsquorum: 50 Prozent; Prozentwerte eigene Berechnung. Die volksbegehrte Landtagsauflösung war damit ,unecht“ gescheitert. Siehe zu diesem Fall näher O. Jung, Direkte Demokratie - Erfahrungen und Perspektiven, veröffentlicht unter: http:// www.infoseiten.slpb.de / fileadmin / daten / dokumente / Direkte_Demokratie_-_Erfahrungen_und_Perspektiven.pdf(Zugriff 10.7.2009), S. $1 \mathrm{f}$.

$31 R$. Thoma , Recht und Praxis des Referendums im Deutschen Reich und seinen Ländern, ZöR VII (1928), 489 (504).

32 Bei kontroversen Themen in einer freien Gesellschaft sind einstellige Prozente an Nein-Stimmen geradezu der Lackmustest für Boykott. - Selbstverständlich läßt sich mit den Methoden der juristischen Zeitgeschichte der jeweilige Boykott genau beschreiben, doch das würde hier $\mathrm{zu}$ weit führen. 
So stellt sich nachgerade die Frage, warum im ersten Fall die Boykottechnik nicht eingesetzt wurde. ${ }^{33}$ Die Antwort ergibt sich aus der atypischen Situation in Bayern 1924. Dort griff nicht, wie üblich, die Opposition zum Mittel der Volksgesetzgebung, um sich punktuell durchzusetzen. Vielmehr war es „die größte, die Landespolitik beherrschende Partei“"34 selbst, die hier eine „Flucht nach vorn“ 35 antrat. Weil die BVP ihre Koalitionspartner nicht zur Unterstützung ihres Verfassungsprojektes zu gewinnen vermochte, versuchte sie den nicht genügenden politischen Konsens im Parlament plebiszitär zu überspielen und schlug den prinzipiell oppositionellen Weg der Volksgesetzgebung ein. Bei dieser Konstellation erschien den Sachgegnern ein Boykott nicht klug, und in der Tat gelang es ihnen, die große Regierungspartei punktuell zu schlagen. Weit entfernt von der verfassungsmäßig erforderlichen Zweidrittelmehrheit der abgegebenen Stimmen, sollte dieses Vorhaben nicht einmal eine einfache Mehrheit „schaffen“, vielmehr wurde es von der Mehrheit der Aktivbürger deutlich abgelehnt. ${ }^{36}$

\section{Exkurs: Zum Vergleich: Erfahrungen mit dem Zustimmungsquorum und mit quorenlosen Volksentscheiden auf Landesebene}

Die beiden Volksentscheide, die unter einem Zustimmungsquorum stattfanden über die Landtagsauflösung in Preußen am 9. August 1931 (Zustimmung der Mehrheit der Stimmberechtigten erforderlich nach Art. 6 Abs. 6 S. 1 Verf.) sowie zum gleichen Thema in Braunschweig am 15. November 1931 (Zustimmung der Mehrheit der Stimmberechtigten erforderlich nach Art. 42 Abs. 3 S. 1 Verf.) -, wurden von den Sachgegnern ,natürlich“ ebenfalls boykottiert. Die Nein-Stimmen-Quote betrug nur 3,8 Prozent ${ }^{37}$ bzw. 5,4 Prozent. ${ }^{38}$ Man verließ sich darauf, daß die Befürworter an dem hohen Quorum scheitern würden.

33 4.279.507 Stimmberechtigte, 3.034.574 abgegebene Stimmen, 161.254 ungültig, 2.873.320 gültig, $1.377 .839=48,0$ Prozent Ja, $1.495 .481=52,0$ Prozent Nein, nach: ZBayStatLA 56 (1924), $291 \mathrm{ff}$.

34 Vgl. Thoma, Recht und Praxis (Fn. 31), 500.

35 Vgl. K. Schönhoven, Die Bayerische Volkspartei 1924-1932, 1972, S. 89.

36 Das volksbegehrte Gesetz war damit „echt“ gescheitert. - Zum Kontext vgl. Rux, Direkte Demokratie (Fn. 24), S. 158 ff.; A. Mittenberger-Huber, Das Plebiszit in Bayern. Eine rechtshistorische Bestandsaufnahme, 2000, S. 94-101.

37 26.587.672 Stimmberechtigte, 10.425.635 abgegebene Stimmen, 243.450 ungültig, 10.182.185 gültig, 9.793.030 Ja, 389.155 Nein, nach: StatJb. Preußen 29 (1933), S. 216 f. „Ja“ in Prozent der gültigen Stimmen: 96,2, „Nein“ 3,8; „Ja“ in Prozent der Stimmberechtigten: 36,8 Prozent, Zustimmungsquorum: 50 Prozent; Prozentwerte eigene Berechnung. Die volksbegehrte Landtagsauflösung war damit ,unecht“" gescheitert.

38 353.391 Stimmberechtigte, 44.595 abgegebene Stimmen, 867 ungültig, 43.728 gültig, 41.358 Ja, 2.370 Nein, nach: Braunschw. StZtg. Nr. 276v. 25.11.1931. „Ja“ in Prozent der gültigen Stimmen: 94,6, „Nein“ 5,4; „Ja“ in Prozent der Stimmberechtigten: 11,7 Prozent, Zustimmungsquorum: 50 Prozent; Prozentwerte eigene Berechnung. Die volksbegehrte Landtagsauflösung war damit „unecht“ gescheitert. 
Wie,,normale“ Abstimmungsergebnisse aussehen, zeigen die quorenlosen Volksentscheide, die es seinerzeit ebenfalls gab: In Schwarzburg-Sondershausen am 25. April 1920 über die Landtagsauflösung: 45 Prozent „Ja“, 55 Prozent „Nein““;3 in Bremen am 9. Januar 1921 über den Rücktritt des Senats: 42,7 Prozent „Ja“, 57,3 Prozent „Nein“;40 in Lübeck am 6. Januar 1924 über den Rücktritt des Senats: 40,1 Prozent „Ja“, 59,9 Prozent „Nein“;41 in Schaumburg-Lippe am 6. Juni 1926 über den Anschluß an Preußen: 46,7 Prozent „Ja“, 53,3 Prozent „Nein“, 42 und in Hessen am 5. Dezember 1926 über die Landtagsauflösung: 47,9 Prozent „Ja“, 52,1 Prozent „Nein““ 4344

Besonders interessant ist der Fall Schaumburg-Lippe. In diesem Land wurden in relativ kurzem Abstand zwei Volksentscheide zur grundsätzlich gleichen Thematik - auch bei dem Versuch der Landtagsauflösung 1924 ging es im Kern um die Frage des Anschlusses an Preußen ${ }^{45}$ - nach zwei verschiedenen Regelwerken durchgeführt. Da andere denkbare Faktoren wie die politische Kultur des Landes, die Mentalität der Bevölkerung und woran man sonst noch denken mag, sich innerhalb von zwei Jahren kaum geändert haben dürften (dafür spricht auch der Ausgang der Landtagswahlen im Zwischenjahr $1925^{46}$ ), läßt dies den Schluß zu, daß die unterschiedlichen Ergebnisse auf jene verschiedenen Regelwerke zurückgingen. Die

39 17.136 Ja, 20.903 Nein, nach: Der Deutsche Nr. 104 v. 5.5.1920; Prozentwerte eigene Berechnung.

40 209.735 Stimmberechtigte, 74.926 Ja, 100.471 Nein, nach: StatJb. der Freien Hansestadt Bremen, Jg. 1929, S. 367; Prozentwerte eigene Berechnung.

4184.462 Stimmberechtigte, 322 ungültige Stimmen, 73.736 gültige Stimmen, 29.596 Ja, 44.140 Nein, nach Lübeckische Blätter 66 (1924), S. 28; Prozentwerte eigene Berechnung.

429.902 Ja, 11.293 Nein, nach: Schaumburg-Lippische Landesanzeigen 1926, S. 254 (Nr. 40 v. 23.6.1926); Prozentwerte eigene Berechnung.

43 876.255 Stimmberechtigte, 427.359 abgegebene Stimmen, 5.188 ungültig, 422.171 gültig, 202.326 Ja, 219.845 Nein, nach: Mitteilungen der Hessischen Zentralstelle für die Landesstatistik 56 (1926), S. 146; Prozentwerte eigene Berechnung.

44 Der Volksentscheid über die Landtagsauflösung in Oldenburg am 17. April 1932 ist atypisch, weil hier trotz Quorenfreiheit (arg. e $\S \S 55$ Abs. 1, 68 Abs. 2 Verf.) zum Boykott aufgerufen wurde. Die Sachgegner ,spielten“ sozusagen nicht ,richtig“, vgl. K. Schaap, Die Endphase der Weimarer Republik im Freistaat Oldenburg 1928-1933, 1978, S. 180 f.

45 Die Begründung des Auflösungsvolksbegehrens führte aus, die Zusammensetzung des Landtags entspreche ,schon seit längerer Zeit nicht mehr dem allgemeinen Volkswillen. Insbesondere steht die Auffassung der Mehrheit des Landtages über den Anschluß des Freistaates an einen benachbarten Großstaat nach Ansicht der Unterzeichneten im Widerspruch zu der Auffassung der Mehrheit des Schaumburg-Lippischen Volkes“, vgl. Bek. v. 7.4.1924, in: Schaumburg-Lippische Landesanzeigen, S. 105 (Nr. 28 v. 9.4.1924).

46 Ein bedeutsames Ergebnis jener Wahlen war, daß nun erstmals die Bürgerlichen die Mehrheit im Landesparlament errangen. Doch die Wählerbewegung war nur gering: Seit 1922 hatten SPD (7 Mandate) und USPD (1 Mandat) eine knappe Mehrheit im 15sitzigen Parlament. Nun war die USPD nicht mehr im Landtag vertreten, die SPD behauptete, sogar mit einem Stimmanteilszuwachs, ihre 7 Mandate, und die KPD schaffte den Einzug in den Landtag nicht. Zählt man die Prozentsätze der drei linken Parteien zusammen, so war ihr Anteil von 50,5 Prozent 1922 lediglich auf 47,5 Prozent 1925 zurückgegangen. Vgl. J. Falter/T. Lindenberger/ S. Schumann, Wahlen und Abstimmungen in der Weimarer Republik. Materialien zum Wahlverhalten 1919-1933, 1986, S. 109. 
Sachgegner wußten eben genau, worauf es ankam: Wann sie am klügsten die Abstimmung boykottierten, und wann sie ,,antreten“ mußten.

So liefert die Weimarer Praxis auf Landesebene - wider manche Skepsis ${ }^{47}$ durchaus Hinweise auf eine Verbindung von Beteiligungsquorum und Boykottstrategie. ${ }^{48}$

Auch auf der Kommunalebene führte zur Weimarer Zeit insbesondere ${ }^{49}$ im Freistaat Sachsen das 50prozentige Beteiligungsquorum der Gemeindeordnung ( $\$ 71$ Abs. 2 S. 8 GemO 1923, § 129 Abs. 2 S. 8 GemO 1925) folgerichtig zu einer ganzen Reihe von Boykottfällen. ${ }^{50}$

\section{Nach 1945}

\section{a) Landesebene}

Die Verfahren auf Landesebene in Rheinland-Pfalz und Nordrhein-Westfalen wurden bislang nicht praktisch.

\section{b) Kommunalebene}

Auf der Bezirksebene in Berlin hat sich unter der seit 2005 geltenden Regelung bereits eine durchaus ansehnliche Praxis angesammelt. ${ }^{51}$ Bislang scheiterten nur

47 Zu skeptisch Wiegand, Direktdemokratische Elemente (Fn. 12), S. 95, mit der nicht weiter spezifizierten Aussage, die Volksgesetzgebungsversuche in den einzelnen Ländern hätten „über Erkenntnisse und Erfahrungen mit der Volksgesetzgebung im Reich nicht hinaus(geführt)".

48 Leider sieht Rux, Direkte Demokratie (Fn. 24), S. 187 f., 192 f., in seiner Würdigung dieser Praxis jene Hinweise nicht, was auch mit seiner Fehleinordnung einiger Fälle zusammenhängen dürfte.

49 Ein 50prozentiges Beteiligungsquorum galt für Sachentscheide (also nicht für die Auflösung des Vertretungsorgans) nach der Städte-, Landgemeinde- und Kreisordnung von Braunschweig (vgl. J.H. Witte, Unmittelbare Gemeindedemokratie der Weimarer Republik. Verfahren und Anwendungsausmaß in den norddeutschen Ländern, 1997, S. 53, 61, 74) und nach der Kreisordnung von Schaumburg-Lippe (S. 151). In dem letztgenannten Land gab es keine Anwendungsfälle (S. 152). Aus der braunschweigischen Praxis (vgl. S. 59 ff., 69-73 f.) ist nur ein Fall bekannt, in dem bei einem (,von oben“ angeordneten) Gemeindereferendum mit einer Beteiligung von 40 Prozent jenes Quorum verfehlt wurde (S. 73). Ob dabei Boykott eine Rolle spielte, ist nicht bekannt. - Die von Witte selbst genannten Fälle, in denen ,einige Verfahren allein am Beteiligungsquorum gescheitert" seien (S. 186 f., 187 Fn. 2), sind nach seinem eigenen Material nicht einschlägig.

50 Vgl. C. Schmidt, Unmittelbare Gemeindedemokratie im mittel- und süddeutschen Raum der Weimarer Republik. Eine Untersuchung von Verfahren und Praxis, 2007, S. 149, 166, 172 (,Jeder, der zur Wahl geht, übt Verrat ...“), 173, 176, 178, 180.

51 Vgl. M. Efler/C. Posselt, Direkte Demokratie in Berlin, in: Heußner/Jung, Mehr direkte Demokratie (Fn. 16), S. 285 (298-302). Zuletzt sei der Bürgerentscheid im Bezirk Tempelhof- 
zwei bürgerbegehrte Projekte an dem 15prozentigen Beteiligungsquorum. Bei der Abstimmung am 27. Januar 2008 im Bezirk Berlin-Spandau ging es um die Bebauung der Halbinsel im Groß-Glienicker See. Der Vorschlag einer Bürgerinitiative fand eine Mehrheit von 86,6 Prozent gegen 13,4 Prozent Ablehnung, während der Gegenvorschlag der Bezirksverordnetenversammlung mit 28,7 Prozent „Ja“ gegen 71,3 Prozent „Nein“ abgelehnt wurde; dies belegt, daß kein Boykott im Spiele war. Die Abstimmungsbeteiligung von nur 13,6 Prozent zeigt aber, daß die zum Bürgerentscheid gestellte Problematik einfach auf nicht genügend Interesse, positiv oder negativ, bei den immerhin 170.141 Stimmberechtigten stieß. ${ }^{52}$

Auch das Bürgerbegehren im Bezirk Mitte gegen die Ausweitung der Parkraumbewirtschaftung am 28. September 2008 scheiterte mit einer Abstimmungsbeteiligung von nur 11,7 Prozent am erforderlichen Quorum. Hier zeigen 20,5 Prozent „Nein“ unter den abgegebenen gültigen Stimmen ${ }^{53}$ ebenfalls, daß kein Boykott stattfand. Es war wohl einfach so, daß das Thema die 214.873 Stimmberechtigten des Innenstadt-Bezirks weitgehend kalt ließ. ${ }^{54}$

\section{c) Italien}

Lehrreich ist schließlich ein Blick zur Seite, nach Italien: Dort fanden seit 1974 bis Mitte 200963 abrogative Referenden auf nationaler Ebene statt. Davon scheiterten - trotz einer Mehrheit unter den Abstimmenden! - 27 Volksentscheide daran, daß sich die Mehrheit der Stimmberechtigten nicht an dem Urnengang beteiligte. Boykott der Abstimmung wird regelmäßig als das probateste Mittel benutzt, um ein mißliebiges direktdemokratisches Projekt zu Fall zu bringen. ${ }^{55} \mathrm{Da}$ das primäre Ergebnis derartiger politischer Veranstaltungen Frustration ist, bedarf keiner Ausführung.

Schöneberg am 7.6.2009 über das Projekt „Das Denkmal Flughafen Tempelhof erhalten - als Weltkulturerbe schützen“ erwähnt, Ergebnis in: ABl. für Berlin, S. 1745.

52 Ergebnis des Bürgerentscheids in Spandau am 27. Januar 2008 in: ABl. für Berlin, S. 446. Prozentwerte der Ja- und Nein-Stimmen: eigene Berechnung. - Siehe auch U. Aulich, Beteiligung am Bürgerentscheid war zu gering. Spandauer lehnen geplantes Wellnesszentrum ab, http://www.berlinonline.de / berliner-zeitung / archiv / .bin / dump.fcgi / 2008 / 0128 / berlin / 0065 / index.html (Zugriff 12.7.2008). Ferner Zweiter Berliner Demokratiebericht von Mehr Demokratie e.V., 2008, S. $48 \mathrm{f}$.

53 Das Ergebnis des Bürgerentscheids in Mitte vom 28. September 2008 wurde (offenbar aus Versehen) bis Ende Juni 2009 noch nicht im „Amtsblatt für Berlin“ bekanntgemacht. Die absoluten Zahlen nach der Internetveröffentlichung des Bezirksamtes Mitte unter http:// www.berlin.de/imperia/md/content/bamitte/buergerdienste/endg_ltiges_ergebnis.pdf (Zugriff 9.6.2009). - Prozentwerte eigene Berechnung.

54 Vgl. R. Nikolow, Streit um Parkgebühren läßt Anwohner in Mitte kalt, in: Tsp. Nr. 20040 v. 29.9.2008.

55 Vgl. Capretti, Direkte Demokratie in Italien (Fn. 16), S. 162; dort auch eine Tabelle mit den Abstimmungsergebnissen (S. 173-177); P. Ridola, Verfassungsrechtliche Probleme und politische Erfahrungen der unmittelbaren Demokratie in Italien, JöR 49 (2001), 369 (383). An den drei Referenden vom 21./22.6.2009 beteiligten sich keine 24 Prozent der Stimmberechtigten, vgl. http://referendum.interno.it/ (Zugriff 26.6.2009). 


\section{Exkurs: Zum Vergleich: Erfahrungen mit dem Zustimmungsquorum und mit quorenlosen Volksentscheiden auf Landesebene}

Diese Erfahrungen mit dem Beteiligungsquorum sind zu kontrastieren mit den deutschen Erfahrungen auf Landesebene mit dem Zustimmungsquorum. Weil dieses nicht erreicht wurde, sind in den letzten zwölf Jahren sechs volksbegehrte Projekte gescheitert, nämlich in Schleswig-Holstein am 30. November 1997 über die Erhaltung des Buß- und Bettages, ${ }^{56}$ in Hamburg am 27. September 1998 über die Änderung der Volksgesetzgebung - ebenso die Konkurrenzvorlage der Bürgerschaft ,$-{ }^{57}$ in Sachsen-Anhalt am 23. Januar 2005 über die Kinderbetreuung, in Hamburg am 14. Oktober 2007 über die ,Stärkung des Volksentscheids“ und in Berlin am 27. April 2008 über „Tempelhof bleibt Verkehrsflughafen“.

Allerdings sahen in den genannten Scheiterns-Fällen die Abstimmungsergebnisse „normal“" aus, d.h. es fand kein Boykott statt: in Schleswig-Holstein 1997 (Buß- und Bettag): 68,2 Prozent „Ja“, 31,8 Prozent „Nein“, in Hamburg 1998 (Änderung der Volksgesetzgebung): 74,1 Prozent „Ja“, 25,9 Prozent „Nein“ bzw. (Konkurrenzvorlage): 60,0 Prozent „Ja“, 40,0 Prozent „Nein“, in Sachsen-Anhalt 2005 (Kinderbetreuung): 60,5 Prozent „Ja“, 39,5 Prozent „Nein“, in Hamburg 2007 („Stärkung des Volksentscheids“): 75,9 Prozent „Ja“, 24,1 Prozent „Nein“, und in Berlin 2008 (Tempelhof): 60,3 Prozent „Ja“, 39,7 Prozent „Nein“.58

Unter den Bedingungen eines Zustimmungsquorums kamen immerhin zwei Volksgesetze zustande, beide in Hamburg: 1998 wurden so in den Hamburger Bezirken Bürgerbegehren und Bürgerentscheid eingeführt: 73,2 Prozent „Ja“, 26,8 Prozent „Nein“; 44,8 Prozent „Ja“ in Prozent der Stimmberechtigten bei einem Zustimmungsquorum von 25 Prozent. ${ }^{59}$ Und 2004 wurde so ein neues Wahlrecht mit mehr Bürgerrechten vom Volk verabschiedet: 66,7 Prozent „Ja“, 33,3 Prozent „Nein“, 21,2 Prozent „Ja“ in Prozent der Stimmberechtigten bei einem Zustimmungsquorum von 20 Prozent. ${ }^{60}$

Die quorenlosen Volksentscheide in Bayern und Sachsen waren natürlich - jedenfalls in der hier interessierenden Hinsicht - unproblematisch. Ihre Daten sind leicht zugänglich. ${ }^{61}$ Es versteht sich von selbst, daß hier lediglich Volksentscheide

56 Vgl. A. Schimmer, „Ihre Stimme für den Bußtag, weil Feiertage unbezahlbar sind“- Der Kampf der Nordelbischen Kirche für die Erhaltung des Buß- und Bettages, in: H.K. Heußner/O. Jung (Hrsg.), Mehr direkte Demokratie wagen. Volksbegehren und Volksentscheid: Geschichte Praxis - Vorschläge, 1. Aufl. 1999, S. 269 (283).

57 Vgl. M. Efler, Der Kampf um Mehr Demokratie in Hamburg, in: Heußner/Jung, Mehr direkte Demokratie (Fn. 56), S. 205 (217 f.); auch in: H.-P. Bull (Hrsg.), Fünf Jahre direkte Bürgerbeteiligung in Hamburg - unter Berücksichtigung von Berlin und Bremen, 2001, S. 77 (84 f.).

58 Zahlen nach O. Jung, Volksentscheide in den deutschen Bundesländern von 1945-2008, in: Heußner/Jung, Mehr direkte Demokratie (Fn. 16), S. 225.

59 Vgl. Efler, Kampf um Mehr Demokratie (Fn. 57), S. 219.

60 Endgültiges Ergebnis des Volksentscheids „Änderung des Hamburger Wahlrechts“ am 13.6.2004 nach: http://fhh.hamburg.de/stadt/Aktuell/wahl/volksabstimmungen/2004/neues20wahlrecht/ergebnis-ve-wahlrecht-pdf,property=source.pdf (Zugriff 6.7.2007).

61 Vgl. Jung, Volksentscheide (Fn. 58), S. 225. Hinzugekommen ist seitdem nur der Volksentscheid über „Pro Reli“ am 26.4.2009 in Berlin. 
als Abschluß eines prinzipiell oppositionellen Verfahrens in Betracht kommen - also der Volksgesetzgebung oder auch etwa des abrogativen Referendums in Italien -, weil nur dort eine Boykottversuchung bestehen kann. Bei den prohegemonialen Verfahren - insbesondere den Verfassungsreferenden, die obligatorisch oder bedingt-obligatorisch in Bayern, Hessen und Bremen vorgesehen sind, wenn also über eine vom Parlament beschlossene verfassungsändernde Vorlage das Volk abstimmen soll -, gibt es nicht nur (jedenfalls in Bayern und Hessen ${ }^{62}$ ) keine Quoren - so daß ein Boykott ,witzlos“ wäre -, sondern vor allem erstrebt die politische Elite natürlich eine überzeugende Affirmation ihrer Politik durch eine große „Ja“-Mehrheit bei starker Beteiligung.

\section{Erklärungen}

\section{Woher kommt die Boykottversuchung?}

Auf den allerersten Blick mutet ein Beteiligungsquorum einleuchtend an. Es geht darum, die Legitimität der direkten Demokratie zu sichern. Deshalb sollen nur jene Abstimmungen zu Volksgesetzen führen, an denen sich (hinreichend) viele Bürger beteiligt haben. Wenn nur (allzu) wenige Bürger bei einem Volksentscheid ihren Willen bekundet haben, würde einem daraus entstehenden Gesetz, das ja für alle verbindlich sein soll, ein Ruch von „Minderheitsherrschaft“ anhaften. Dieses politische Ziel ausreichender Partizipation wird wohl allgemein gebilligt.

Aber ist zur Erreichung dieses Ziels das gewählte Mittel geeignet? Beim Beteiligungsquorum wird das Verhalten des Bürgers zweimal gezählt:

- einmal als staatsbürgerliche Entscheidung, nämlich ob er an die Urnen kommt, um sich - inhaltlich wie auch immer (Ja, Nein, Ungültig) - an der Abstimmung $\mathrm{zu}$ beteiligen, und

- ein zweites Mal als politische Willensbekundung, bei der er für oder gegen den zum Volksentscheid gestellten Entwurf votiert.

Dabei wird stillschweigend von einem gewissermaßen naiven Verhaltensmuster des Bürgers ausgegangen, der erst - sei es aus sachlichem Interesse, sei es aus staatsbürgerlichem Pflichtgefühl - sich zum Gang in das Stimmlokal entschließt und dann in Ruhe darauf wartet, welches Votum sich wohl bei der Abstimmung mit Mehrheit durchgesetzt hat.

Nun sind schon die Bürger in Wirklichkeit nicht naiv und können durchaus taktisch denken. ${ }^{63}$ Vor allem aber ist in einem modernen Großstaat mit festen politi-

62 In Bremen gilt auch für diesen Fall nach Art. 72 Abs. 1 Verf. ein 25prozentiges Zustimmungsquorum.

63 Zur Empirie: Der Anteil „strategischer Wähler“, die also das Stimmensplitting bewußt handhabten, wird bei den vier Bundestagswahlen 1994 bis 2005 in den Wahlkreisen Ostdeutschlands auf bis zu neun Prozent geschätzt, vgl. M. Herrmann, Die Bedeutung strategischen Erststimmen-Wählens bei deutschen Bundestagswahlen, in: C. Henning/E. Linhart/S. Shikano 
schen Strukturen das Abstimmungsverhalten keineswegs bloß Sache des Entschlusses der einzelnen Individuen. Vor einem Volksentscheid geben Parteien und andere große Verbände Parolen aus. Parteien sind aber noch viel weniger als einzelne Bürger passive Zuschauer des Abstimmungsgeschehens, die abwarten, wie wohl die Beteiligung ausfallen werde, um dann das nach dem jeweiligen Regelwerk maßgebliche Quorum anzuwenden. Parteien sind vielmehr machtorientierte Akteure, wollen ihre politischen Ziele durchsetzen und gehen dabei selbstverständlich auch taktisch vor. Die Abstimmungsbeteiligung ist daher für Parteistrategen keine von außen kommende, unbeeinflußbare Größe, die einfach hinzunehmen wäre, sondern sie stellt eine für politische Einwirkung durchaus offene Variable dar.

An der Zusatzbedingung eines Beteiligungsquorums anzusetzen verlockt nun Parteistrategen aus vier Gründen:

- Wirkungsvolle Behinderung der Befürworter: Das Beteiligungsquorum wirkt insofern ambivalent, als auch jede abgegebene Nein-Stimme die Befürworter eines Projekts - einmal ihre Mehrheit an den Urnen unterstellt - dem Ziel der Gültigkeit der Abstimmung näher bringt. Warum sollten die Sachgegner ihnen diesen Dienst erweisen? Durch Boykott wird den Befürwortern die Last allein aufgebürdet, die nötige Beteiligung zu mobilisieren. Das Beteiligungsquorum wird durch dieses taktische Verhalten also unter der Hand zu einem Zustimmungsquorum umgestaltet; dies legt die Hürde vor einem Sacherfolg rechnerisch doppelt so hoch. ${ }^{64}$

- Ökonomische Überlegungen: Jede Organisation mit prinzipiell knappen Ressourcen entschließt sich schwerlich zu einem kostspieligen Abstimmungskampf, um gegen ein direktdemokratisches Projekt eine Nein-Mehrheit an den Urnen zu mobilisieren, wenn die vergleichsweise billige Möglichkeit besteht, durch Boykott die ganze Abstimmung unter die Gültigkeitsgrenze (wegen mangelnder Beteiligung) zu drücken und das mißliebige Projekt auf diese Weise zunichte zu machen.

- Erwägungen des politischen Prestiges: Je weniger eine Organisation ihrer eigenen „Bataillone“ sicher ist, um so mehr wird sie das Risiko eines offenen Kräftemessens bei der Abstimmung (das sie ja verlieren kann!) meiden und statt dessen versuchen, ihr Ziel anders - ohne Auszählung - zu erreichen, indem sie die Befürworter eines direktdemokratischen Projekts verfahrensmäßig ins Leere laufen läßt.

(Hrsg.), Parteienwettbewerb, Wählerverhalten und Koalitionsbildung. Festschrift zum 70. Geburtstag von Franz Urban Pappi, 2009, S. 81 (103).

64 Zur Verdeutlichung: Im „,naiven“ Szenario können die Befürworter mit 26 Prozent „Ja“-Stimmen bei 25 Prozent „Nein“-Stimmen (immer bezogen auf die Gesamtheit der Stimmberechtigten) siegen, weil sie nicht nur an den Urnen die Mehrheit erreicht, sondern auch das Beteiligungsquorum von 50 Prozent erfüllt haben. Boykottieren die Sachgegner effektiv, müssen die Befürworter alleine 51 Prozent der Stimmberechtigten für sich gewinnen, um Erfolg zu haben. 
So gehörte es nachgerade zum kleinen politischen Einmaleins in Weimar:

- Boykott war effektiv - man konnte, da nun das Abstimmungsgeheimnis faktisch aufgehoben war (wer überhaupt zur Abstimmung ging, ,outete“ sich als Befürworter), den Sozialdruck nutzen.

- Boykott war billig - man sparte sich die ganze Mobilisierungslast einer „Stimmt mit Nein"-Kampagne.

- Boykott war sicher - gegen die nachträgliche interpretative Vereinnahmung sämtlicher Nichterschienener als überzeugte Sachgegner konnten jene sich ja schlecht wehren.

Der vierte Grund ist sozusagen die Umkehrung des ersten: Die Sachgegner haben nicht nur keinen Anlaß, die Befürworter dem Ziel der Gültigkeit der Abstimmung näher zu bringen. Sie haben vor allem ein völlig legitimes Interesse, nicht ihre eigene Sache zu schädigen. Just diese Gefahr besteht aber angesichts des spezifischen Risikos, das ein Beteiligungsquorum für die abstimmenden Sachgegner birgt: daß sie nämlich mit ihrem Gang zu den Urnen dem volksbegehrten Projekt über die Quorenhürde helfen. Dann hätten sie mit ihrem „Nein“ die Gültigkeit der Abstimmung bewirkt und so der „Ja“-Mehrheit den schlußendlichen Erfolg verschafft.

Dieses Risiko besteht immer. Es wird aber besonders deutlich in Grenzfällen, wenn die Befürworter das Quorum fast aus eigener Kraft - aber doch nicht ganz „geschafft" haben und dann den letztendlichen Erfolg einigen zusätzlichen NeinStimmen verdanken.

Ein Beispiel: Ein dramatischer Fall spielte am 18. April 1999 in Italien - zugleich ein Beleg für das „Vergiftete“ eines Beteiligungsquorums: 24.447.521 Bürger gingen zu den Stimmlokalen, von denen die überwältigende Mehrheit - 91,5 Prozent der gültigen Stimmen - für die vorgeschlagene Wahlrechtsänderung votierte. Gleichwohl kam das Gesetz nicht zustande, weil diese 24,5 Millionen Abstimmenden „nur“ 49,6 Prozent der Stimmberechtigten ausmachten; 65 es fehlten ganze 0,4 Prozent der Stimmberechtigten zur Erfüllung des Beteiligungsquorums. Wenn etwa 207.000 Bürger mehr zu den Urnen gegangen wären, um das vorgeschlagene Projekt mit ihrer Stimme abzulehnen, hätten sie im Ergebnis dessen Sieg bewirkt.

Und ein Szenario: „Ein Gesetz ist durch Volksentscheid angenommen“ - bestimmte Art. 63 Abs. 2 a.F. Verf. -, ,,wenn sich entweder mindestens die Hälfte der zum Abgeordnetenhaus von Berlin Wahlberechtigten am Volksentscheid beteiligt und die Mehrheit für das Gesetz stimmt oder bei geringerer Stimmbeteiligung mindestens ein Drittel der Wahlberechtigten für das Gesetz stimmt.“ Daß diese „Berliner Doppelhürde" hochproblematische Effekte zeitigen kann, wurde in der Literatur öf-

65 Daten nach: http://c2 d.unige.ch/int/voteres.php?entit=84\&vote=1120\&lang= (26.3.2001). S. Jung, Die Logik direkter Demokratie, 2001, S. 266 Fn. 225, erschien dieser Fall zu Recht als ,trauriger Höhepunkt“ des Effekts des Beteiligungsquorums, „Boykottstrategien herauszufordern“. 
ters beklagt, ${ }^{66}$ aber letztere wurden nie, soweit ersichtlich, aus der Sicht von Parteistrategen durchgespielt (was auch damit zusammenhängen mag, daß diese Klausel nie verfassungspraktisch wurde). Das sei hier - natürlich wieder für einen „Grenzfall“" - nachgeholt. Angenommen, die Befürworter eines volksbegehrten Entwurfs hätten eine deutliche Mehrheit an den Urnen, die allerdings nur 32 Prozent der Stimmberechtigten ausmachte. Die Nein-Stimmen beim Volksentscheid machten umgerechnet 17 Prozent der Stimmberechtigten aus. Damit hätte das Projekt bei einer Beteiligung von 49 Prozent das Quorum von 50 Prozent verfehlt und auch die in diesem Falle erforderliche Zustimmung von 33 Prozent nicht erreicht; es wäre trotz klarer Mehrheit unter der Aktivbürgerschaft „unecht“ gescheitert. Hätten nur 25.000 Stimmberechtigte mehr den Gang zu den Abstimmungslokalen angetreten, um den volksbegehrten Entwurf abzulehnen, hätten sie damit die Beteiligung über das 50prozentige Quorum gehoben, maßgeblich wäre nun die Mehrheit an den Urnen (hier 32 zu 18 Prozent, jeweils der Stimmberechtigten), und das Projekt wäre erfolgreich gewesen.

Dieses Risiko ist unzumutbar. Jene Abwehrmethoden - vom Totschweigen bis zum Boykott - gehen also nicht (nur) auf einen Mangel an demokratischer Moral bei den Akteuren zurück oder - in Weimar - auf eine politische Kultur, die stark von einem Freund-Feind-Denken geprägt war. Vielmehr ermöglicht ein solches Regelwerk nicht nur, sondern es gebietet geradezu staatsbürgerliche Passivität. Die Sachgegner müssen es von der immanenten Logik des Reglements her den Befürwortern überlassen, das Beteiligungsquorum aus eigenen Kräften zu überwinden.

Zwischenergebnis: Machtorientierung sowie Kosten-und-Risiko-Kalkül führen angesichts eines Beteiligungsquorums also immer zur Parole der Nichtbeteiligung. Ein Instrument, das angeblich eine hinreichende Partizipation sichern soll, drückt in der Realität zuverlässig die politische Beteiligung. Das Beteiligungsquorum wirkt dysfunktional. ${ }^{67}$ Das Instrument ist falsch konzipiert. Man hat offenbar von der Erwünschtheit einer hinreichenden Beteiligung ,schlicht auf die Nützlichkeit eines entsprechenden Quorums geschlossen und dabei ein richtiges Ziel mit dem falschen Mittel zu erreichen versucht. Jedes Quorum setzt massive Fehlanreize.“68 Damit

66 So nannte sie G. Jürgens, Die anderen Bundesländer, in: Heußner/Jung, Mehr direkte Demokratie (Fn. 56), S. 223 (230), ein Beispiel dafür, ,welche Kuriositäten auf dem Gebiet der direkten Demokratie sich Parlamentarier bisweilen ausdenken“. - Rux, Direkte Demokratie (Fn. 24), S. 759 Fn. 4, 787, kritisiert mit Recht „die äußerst merkwürdigen Konsequenzen“ dieses ,geradezu absurden Quorums“, stellt sich aber nicht die Frage, wie die Parteien mit einem solchen Regelwerk gegebenenfalls taktisch umgehen würden.

67 Lapidar hat Jung, Logik (Fn. 65), S. 94, eine scharfsinnige Demokratie-Analytikerin, festgestellt: „Problematisch sind Beteiligungsquoren allerdings insofern, als ihre Anwendung geradezu systematisch verhindert, daß dieses letztere Ziel [d.h. die Maximierung von Beteiligung] erreicht wird. Denn existieren Beteiligungsquoren, so wird das Fernbleiben von der Abstimmung für die Gruppe der Gegner einer Vorlage zur erfolgversprechenden und zugleich bequemen Strategie.“

68 Vgl. O. Jung, Grundsatzfragen der direkten Demokratie, in: Kost, Direkte Demokratie (Fn. 5), S. 312 (328). Siehe ders., Die Reform der direkten Demokratie im Saarland - Teil I: Problemlage und Grundfragen, Teil II: Verfassungsändernde Volksgesetzgebung und Finanztabu -, LKRZ 2008, 41, 91 (93). 
entpuppt sich das Beteiligungsquorum als ein Widerspruch in sich: Demokratie lebt von der Aktivität ihrer Bürger. Partizipationsangebote müssen auch angenommen werden - und werden können. Wenn es Wahlen gibt, müssen die Detailarrangements so getroffen werden, daß möglichst viele Bürger wählen gehen (können). Entsprechendes gilt, wenn in direktdemokratischer Ergänzung die Bürger aufgerufen sind, sachunmittelbar zu entscheiden: Dann muß das institutionelle Arrangement so beschaffen sein, daß möglichst viele Bürger zu den Urnen kommen und sich für Ja oder Nein entscheiden. ${ }^{69}$ Eine Abstimmungsklausel, die eine Seite - die Sachgegner mit rationalen Gründen zur Nichtbeteiligung an dem „Volksentscheid“ anhält, verstößt gegen den Geist der Demokratie.

\section{Exkurs: Gilt dies auch für das Zustimmungsquorum?}

Gelegentlich wird argumentiert, solche Negativerscheinungen gebe es nur bei Beteiligungsquoren, während bei einem Zustimmungsquorum ein Boykottaufruf nicht sinnvoll sei. ${ }^{70}$ Doch dies ist so nicht richtig. Zwar interessieren bei einem Zustimmungsquorum in der Tat - wiederum eine „Ja“-Mehrheit an den Urnen unterstellt die „Nein“-Stimmen praktisch gar nicht; bei einem 50prozentigen Zustimmungsquorum können sie sogar logisch außer Betracht bleiben. Damit entfällt der gerade behandelte vierte Grund. Es trifft auch zu, daß die rechnerische Verdoppelung der Hürde nicht möglich ist.

- Aber auch bei einem Zustimmungsquorum kann ein Boykottaufruf z. B. das Abstimmungsgeheimnis praktisch aufheben, damit den Einsatz von Sozialdruck ermöglichen und so den Befürwortern das Erreichen der erforderlichen ,Ja“-Stimmen erheblich erschweren.

- Auch in diesem Falle werden die Kräfte, die das vorgeschlagene Projekt ablehnen, eine politische Kosten-Nutzen-Rechnung anstellen, ob eine Mobilisierung für Nein oder die Ausgabe der Boykott-Parole günstiger ist. Die Versuchung wird wiederum übermächtig sein, anstatt die Befürworter mit hohem Aufwand (bei Gefahr des Mißerfolgs!) an den Urnen zu schlagen, sie unter weit geringeren Kosten verfahrensmäßig ins Aus zu manövrieren.

- Auch angesichts eines Zustimmungsquorums werden die Parteistrategen das Risiko einer offenen Niederlage scheuen und alles tun, um nicht in die Situation zu geraten, daß sie - in jeder Bedeutung des Wortes - ,ausgezählt“ werden.

69 Vgl. Neumann, Sachunmittelbare Demokratie (Fn. 4), S. 386.

70 Vgl. H.-D. Horn, Mehrheit im Plebiszit. Zur Voraussetzung eines Zustimmungsquorums bei Volks- und Bürgerentscheiden, Der Staat 38 (1999), 399 (409). - Überzeugend argumentiert dawider Neumann, Sachunmittelbare Demokratie (Fn. 4), S. 379-383. 
Der Unterschied ist also nur gering: Während ein Beteiligungsquorum die Sachgegner nachgerade zum Boykott zwingt, „empfiehlt“ sich dieser „nur“ bei einem Zustimmungsquorum. ${ }^{71}$

Um dies an einem hypothetischen Beispiel zu illustrieren: Vor dem Volksentscheid zur Fürstenenteignung 1926 behaupteten die Sachgegner, das vorgeschlagene Enteignungsgesetz verstoße gegen die Eigentumsgewährleistung der Verfassung (Art. $153 \mathrm{WRV}$ ), sei mithin verfassungswidrig bzw., was damals akzeptiert wurde, eine Verfassungsdurchbrechung, und deshalb gelte nicht das 50prozentige Beteiligungsquorum des Art. $75 \mathrm{WRV}$, sondern es greife das 50prozentige Zustimmungsquorum des Art. 76 Abs. 1 S. 4 WRV. ${ }^{72}$ Wenn das nicht nur ein weiterer Versuch des Verbaus - die psychologische Erschwerung der erforderlichen Massenmobilisierung - gewesen wäre, wenn also tatsächlich jener Volksentscheid nach dem Weimarer Regelwerk für eine verfassungsändernde Volksgesetzgebung stattgefunden hätte, kann kein Zweifel bestehen, daß die Sachgegner ihre Boykottstrategie beibehalten, ja erst recht forciert hätten. Und für die Befürworter des Enteignungsprojekts hätte sich - der oben erwähnte Effekt der „Umwandlung“ - auch nicht so viel geändert: „20 Millionen waren im einen wie im anderen Falle zu mobilisieren.“"73

$\mathrm{Zu}$ beachten ist allerdings, daß diese wirklichen „Weimarer Erfahrungen“ nicht ohne weiteres auf die Gegenwart zu übertragen sind. In Hamburg haben 1998 und 2007 zwei Volksentscheide unter der Bedingung eines 50prozentigen Zustimmungsquorums stattgefunden; es ging jeweils um Verfassungsänderungen zur Änderung der Volksgesetzgebung bzw. zur Stärkung des Volksentscheids. Beide scheiterten, weil die „Ja“-Mehrheit an den Urnen „nur“ 45,5 bzw. 29,6 Prozent der Stimmberechtigten ausmachte. Aber in beiden Fällen kam es nicht zum Boykott, wie 25,9 bzw. 24,1 Prozent „Nein“-Stimmen belegen. ${ }^{74}$ Offensichtlich kommen für die Wirkung selbst einer so hohen Quorenhürde noch weitere Faktoren in Betracht. Dazu gehört sicherlich das in den behandelten Weimarer Fällen nicht bestehende Erfordernis einer qualifizierten (Zweidrittel-)Mehrheit der Abstimmenden nach Art. 50 Abs. 3 Satz 5 a.F. Hmbg.Verf. Eine positive Rolle spielte aber auch die bei den Akteuren und in der Öffentlichkeit herrschende politische Kultur, bei der sich, wer zum Boykott hätte aufrufen wollen, demokratisch-moralisch disqualifiziert hätte.

\section{Welchen Einfluß hat die Quorenhöhe?}

Für die beiden Volksbegehren auf Reichsebene und für die vier Volksbegehren auf Landesebene der Weimarer Zeit, die bei der Abstimmung „unecht“ scheiterten, galt jeweils ein Beteiligungsquorum mit dem recht hohen Satz von 50 Prozent. In allen

71 Ähnlich Neumann, Sachunmittelbare Demokratie (Fn. 4), S. 381: „Das Beteiligungsquorum provoziert den Boykott förmlich, das Zustimmungsquorum vermag ihn bzw. die Diskussionsverweigerung nicht auszuschließen.“

72 Vgl. Jung, Volksgesetzgebung (Fn. 17), S. 827-832.

73 Vgl. a.a.O., S. 831.

74 Vgl. Jung, Volksentscheide (Fn. 58), S. 225. 
diesen Fällen griffen die Sachgegner zur Boykottstrategie und hatten damit Erfolg. So stellt sich die Frage, ob die eben erklärte Boykottversuchung weniger stark wirkt, wenn die Sätze geringer sind, also die Beteiligung von ,nur“ 25 Prozent der Stimmberechtigten (wie in Rheinland-Pfalz) oder von „lediglich“ 15 Prozent (wie beim Bürgerentscheid auf Bezirksebene in Berlin) verlangt wird. Empirie dazu gibt es nur für die letztgenannte Konstellation. Hier wurde oben bereits gezeigt, daß in den beiden Fällen, in denen bislang das Anliegen eines Bürgerbegehrens am Beteiligungsquorum ,unecht“ scheiterte, ausweislich der „Nein“-Stimmen von 13,4 bzw. 20,5 Prozent kein Boykott im Spiele war. Zusätzlich kann auf einen bemerkenswerten Fall verwiesen werden, in dem ein bürgerbegehrtes Projekt (im auch überregional beachteten Fall „Rudi-Dutschke-Straße“) beim Bürgerentscheid echt scheiterte. D.h., hier „trat“ die Gegenseite ,an“, ging das Risiko der ambivalenten Wirkung des Beteiligungsquorums ein und mobilisierte für die Abstimmung am 21. Januar 2007 eine „Nein“-Mehrheit an den Urnen wider das Projekt des Volksbegehrens. ${ }^{75}$ In diesem Falle hatte ,das aktive Mitbestimmen über das passive Hoffen auf das Nichterreichen des Quorums gesiegt" ${ }^{76}$

Die gestellte Frage ist also zu bejahen. Allerdings sind niedrigere Beteiligungsquoren nur deshalb weniger gefährlich, weil zugleich die Wahrscheinlichkeit abnimmt, daß es überhaupt zu der kritischen Konstellation kommt. Umgekehrt formuliert: Es ist entsprechend wahrscheinlicher, daß die Befürworter eines direktdemokratischen Projekts die Beteiligungshürde aus eigenen Kräften nehmen - und es insoweit (d.h. unter Quorengesichtspunkten) auf die Nein-Stimmen gar nicht mehr ankommt. Damit sinkt zugleich der Boykottanreiz.

Doch auch bei einem niedrigen Beteiligungsquorum bleibt der aleatorische Charakter der Abgabe einer „Nein“-Stimme. In Formeln: Bei einem 50prozentigen Beteiligungsquorum gilt beispielsweise: 48 Prozent „Ja“ +3 Prozent „Nein“ $=51$ Prozent Beteiligung $\rightarrow$ Volksentscheid gültig. Bei einem 15prozentigen Beteiligungsquorum gilt etwa: 14 Prozent „Ja“ +2 Prozent „Nein“ $=16$ Prozent Beteiligung $\rightarrow$ Bürgerentscheid gültig. Oder als allgemeine Maxime formuliert: Wenn die Befürworter eines direktdemokratischen Projekts das Beteiligungsquorum nicht aus eigenen Kräften „schaffen“, ist, je näher sie an die Quorenhürde herankommen, die Gefahr um so größer, daß schon relativ wenige Gegner mit ihren Nein-Stimmen dem eigentlich abgelehnten Projekt ungewollt zum Erfolg verhelfen. - Darauf ist unter C. näher einzugehen.

\section{Exkurs: Gilt dies auch für das Zustimmungsquorum?}

Für die oben erwähnten Fälle ,unechten“ Scheiterns auf Landesebene nach 1945 in Schleswig-Holstein 1997 (Buß- und Bettag), Sachsen-Anhalt 2005 (Kinderbetreu-

75 Bek. des Ergebnisses des Bürgerentscheides in Friedrichshain-Kreuzberg am 21.1.2007 v. 26.1.2007, ABl. für Berlin, S. 278. Vgl. Zweiter Berliner Demokratiebericht von Mehr Demokratie e.V., 2008, S. $49 \mathrm{f}$.

76 A.a.O., S. 28. 
ung) und Berlin 2008 (Tempelhof) galt jeweils ein Zustimmungsquorum von 25 Prozent (die beiden versuchten Verfassungsänderungen in Hamburg 1998 und 2007 mit einem 50prozentigen Zustimmungsquorum wurden oben schon behandelt). Gleichwohl war, wie die „Nein“-Stimmen-Anteile von 31,8, 39, 5 und 39,7 Prozent zeigen, keine Boykottsituation gegeben. ${ }^{77}$ Auch hier sei zusätzlich auf einen jüngsten, bemerkenswerten Fall echten Scheiterns in Berlin („Pro Reli“) verwiesen. Weit entfernt davon, darauf zu setzen, daß die Initiatoren unter den strukturellen Rahmenbedingungen der Stadt das 25prozentige Zustimmungsquorum „nie“ schaffen würden, „trat" die Gegenseite „an“ („Pro Ethik“), mobilisierte ihrerseits und brachte beim Volksentscheid am 26. April 2009 den Initiatoren des Volksbegehrens eine empfindliche Niederlage bei. Die Mehrheit der Abstimmenden schickte deren Gesetzentwurf - schweizerisch gesprochen - „bachab“. ${ }^{78}$

Im Ergebnis scheint die Höhe der Sätze beim Quorum eine erhebliche Rolle zu spielen. Ein 15prozentiges Beteiligungsquorum auf Kommunalebene bzw. ein 25prozentiges Zustimmungsquorum auf Landesebene verführen nach dem vorliegenden Fallmaterial nicht mehr zum Boykott. Über die reine Zahlenbetrachtung hinaus ist aber auch die gegenüber der Weimarer Zeit gewandelte politische Kultur zu bedenken. Boykott ist demokratisch verpönt, und die Akteure beachten dies auch. Das heißt nun nicht, daß wir in einer heilen Welt der direkten Demokratie lebten. Auch wenn man keinen offenen Boykottaufruf alten Stils mehr wagt, können die Sachgegner doch durch Verweigerung der inhaltlichen Diskussion die Intensität der Sachauseinandersetzung und deren öffentliche, vor allem mediale, Beachtung „drücken“. ${ }^{79}$ Damit erfährt ein direktdemokratisches Projekt selbst im Kreise derer eine geringere Aufmerksamkeit, die eigentlich dafür aufgeschlossen sind oder sein könnten. ${ }^{80}$ Dies ist die moderne Form, einen volksbegehrten Entwurf zu hintertreiben. Daher wirkt der Abstimmungskampf der Sachgegner, abzulesen am Mitteleinsatz und dem Temperament des Engagements, im allgemeinen doch deutlich matter als in jenen Ländern, in denen ein quorenloser Volksentscheid abgehalten wird, alle wissen: „Jetzt gilt’s!“ und die Sachgegner sich ihrerseits anstrengen müssen, eine Nein-Mehrheit an den Urnen zu mobilisieren. Unter Quorenbedingungen scheinen sich die Sachgegner doch immer noch darauf zu verlassen, daß sie den volksbegehrten Entwurf, wenn er schon eine Mehrheit an den Urnen erreicht, doch noch über die Nichterfüllung des Quorums ,abfangen“ können.

77 Zum Berliner Volksentscheid im Tempelhof-Fall vgl. Zweiter Berliner Demokratiebericht von Mehr Demokratie e.V., 2008, S. $16 \mathrm{ff}$.

78 Ergebnis des Volksentscheids am 26.4.2009 in Berlin ,über die Einführung des Wahlpflichtbereichs Ethik/Religion“ nach Bek. des Endgültigen Ergebnisses v. 5.5.2009, ABl. für Berlin, S. 1186. Siehe dazu O. Jung, Pro Reli. Der Volksentscheid über den Religionsunterricht in Berlin am 26. April 2009, ZfDD 21 (2009), H. 2 [Nr. 82], 17 ff. sowie den Hinweis im Beitrag von C. Pestalozza in diesem Band (S. 299 [317]).

79 Vgl. Neumann, Sachunmittelbare Demokratie (Fn. 4), S. 380

80 Vgl. a.a.O., S. 384. 


\section{Die Gefahr des negativen Stimmgewichts}

\section{Das Problem aus einem anderen Blickwinkel}

Bis hierher wurde die Problematik des Beteiligungsquorums aus politikwissenschaftlicher Sicht behandelt. Die Perspektive ging ,von oben“ auf das demokratische System und vor allem auf das Verhalten von Großakteuren (Parteien und ihren Strategen) in diesem. Dafür wurden Fälle aus der deutschen und ausländischen Abstimmungsgeschichte sowie dazugehörige hypothetische Varianten behandelt. Als Ergebnis zeigte sich, daß diese Klauseln gegen den Geist der Demokratie verstoßen.

Nun soll ein anderer Blickwinkel eingenommen werden. Aus der Sicht des Verfassungsrechts wird jetzt gleichsam „,von unten“ betrachtet, wie einzelne Stimmbürger ein Beteiligungsquorum erleben, wird insbesondere geprüft, ob dessen programmiertes Funktionieren ihre staatsbürgerlichen Grundrechte verletzt, vor allem die klassischen Wahlrechtsgrundsätze, die ja für Abstimmungen in einer rechtsstaatlichen Demokratie entsprechend gelten. Dazu werden Szenarien entworfen, wie sie gegenwärtig in Deutschland jederzeit vorkommen können.

\section{Szenarien}

\section{Verfassungsändernde Volksgesetzgebung in Nordrhein-Westfalen}

Angenommen, von 13,2 Millionen Stimmberechtigten ${ }^{81}$ haben bis zum Nachmittag 6,5 Millionen ihre Stimme abgegeben, davon haben 5 Millionen mit „Ja“ und 1,5 Millionen mit „Nein“ gestimmt. Bei einer Momentaufnahme wäre also das Erfordernis, daß zwei Drittel der Abstimmenden dem Gesetzentwurf zustimmen, erfüllt, das Beteiligungsquorum von mindestens der Hälfte der Stimmberechtigten jedoch verfehlt. Bis dahin wäre der Volksentscheid also „unecht“ gescheitert und der zugrundeliegende Gesetzentwurf nicht angenommen. Nun findet diese Momentaufnahme ja nicht statt, weil realiter erst nach Schluß der Abstimmungshandlung ausgezählt wird, und die Ergebnisse von Nachabstimmungsbefragungen dürfen, von allen methodischen Vorbehalten abgesehen, nicht vor Ablauf der Abstimmungszeit veröffentlicht werden. ${ }^{82}$ So machen sich also in den letzten Stunden vor Schluß der Abstimmung noch einmal 100.000 Sachgegner auf und stimmen mit „Nein“ ab. Folge: An der Zweidrittelmehrheit der Befürworter ändert sich nichts, aber diese 100.000 „Nein“-Stimmen haben die Beteiligung auf 6,6 Millionen erhöht, das Beteiligungsquorum ist erfüllt, der Volksentscheid gültig und das Gesetz angenommen (vgl. Art. 69 Abs. 3 Satz 3 Verf. NRW).

81 Angelehnt an die Zahl von 13.239.170 Stimmberechtigten bei der Landtagswahl 2005.

82 Auch wenn das nordrhein-westfälische Gesetz über das Verfahren bei Volksinitiative, Volksbegehren und Volksentscheid (VIVBVEG) in der Fassung der Bek. v. 1.10.2004 keine entsprechende Vorschrift enthält, ist doch davon auszugehen, daß § 25 Abs. 3 LWahlG entsprechend anzuwenden ist. 


\section{Einfache Volksgesetzgebung in Rheinland-Pfalz}

Diesmal angenommen, von 3 Millionen Stimmberechtigten ${ }^{83}$ haben bis zum Nachmittag 376.000 mit „Ja“ und 371.000 mit „Nein“ abgestimmt. Man liefert sich also ein „Kopf-an-Kopf“-Rennen, und das mag sogar bekannt sein: Mit dem heutigen Stand demoskopischer Techniken lassen sich Abstimmungsergebnisse grundsätzlich ebenso treffsicher voraussagen wie Wahlergebnisse, aber auch das Gefühl während des Abstimmungskampfes kann schon leiten. So versuchen 4.000 Sachgegner im letzten Moment, doch noch den Sieg zu erringen und den volksbegehrten Entwurf abzulehnen. Dies mißlingt; mit 376.000 „Ja“ zu 375.000 „Nein“ bleibt es bei der einfachen Mehrheit für den Gesetzentwurf. Aber diese 4.000 Sachgegner haben die Beteiligung auf insgesamt 751.000 gehoben, und damit ist das 25 prozentige Beteiligungsquorum erfüllt; der Volksentscheid ist gültig und der Gesetzentwurf angenommen (vgl. Art. 109 Abs. 4 S. 3 Verf. RP).

\section{Bürgerentscheid in Berlin}

Angenommen, im Bezirk Mitte haben von 215.000 Stimmberechtigten ${ }^{84}$ schon 20.000 mit „Ja“ und 12.000 mit „Nein“ abgestimmt. Wenn jetzt noch 300 Bürger hinzukommen und mit „Nein“ stimmen, ist der Bürgerentscheid gültig, weil das 15prozentige Beteiligungsquorum (hier: 32.250 Stimmen) erreicht wurde; die von jenen 300 abgelehnte Vorlage ist angenommen (vgl. § 47 Abs. $1 \mathrm{~S} .1$ BezVG Berlin).

In allen drei Szenarien wurden keine Boykottsituation angenommen und keine unwahrscheinliche Stimmenverteilung (keine „Ausreißer") gewählt. Das gemeinsame Ergebnis ist, daß die letzten Sachgegner, die sich als Staatsbürger betätigten und ihren politischen Willen bekundeten, mit ihrem „Nein“ - ohne es zu ahnen das Gegenteil dessen erreichten, was sie beabsichtigten: Sie verhalfen der von ihnen abgelehnten Abstimmungsvorlage zum Erfolg.

\section{Beurteilung}

1. Das Wahlrechtsurteil des Bundesverfassungsgerichts vom 3. Juli 2008 als Maßstab

Ist dieser potentielle Effekt des Beteiligungsquorums in Ordnung? Oder zwar nicht in Ordnung, aber hinzunehmen? Als Maßstab wird hier das Wahlrechtsurteil des Bundesverfassungsgerichts vom 3. Juli 2008 genommen, das eine spezielle Problematik im Falle von Überhangmandaten bei der Bundestagswahl entschied. Das Wahlrecht kennt hier die Paradoxie im Verfahren der Mandatszuteilung, ,dass ein 
Zugewinn von Zweitstimmen einer Partei zu einem Mandatsverlust bei genau dieser Partei und umgekehrt die Verringerung der Anzahl der Zweitstimmen zu einem Mandatsgewinn führen kann". ${ }^{85}$ Dieser Effekt heißt negatives Stimmgewicht oder inverser Erfolgswert. Der den Wahlprüfungsbeschwerden zugrunde liegende Fall lag dabei besonders kraß, weil es sich um eine Nachwahl nach dem plötzlichen Versterben einer Direktkandidatin handelte, so daß vor Durchführung dieser einen Wahl im Wahlkreis 160 in Dresden das gesamte sonstige Bundestagswahlergebnis bereits vorlag. In der Presse wurden denn auch in den Tagen vor der Nachwahl Berechnungen publiziert, ,dass die CDU bei einer Zweitstimmenanzahl von mehr als 41.225 Stimmen ein Mandat verlieren, bei einer niedrigeren Zweitstimmenzahl jedoch ein Mandat gewinnen könnte“ “ ${ }^{86}$ Dementsprechend wurden Splitting-Auswege empfohlen.

Die Gründe für diesen „Wahlfehler“ können hier auf sich beruhen, desgleichen die Lösungsmöglichkeiten für das dahintersteckende Sachproblem. ${ }^{87}$ Hier interessieren aber die Einschätzung dieses Wahlfehlers durch das Gericht und die rechtlichen Folgerungen. Ausgangspunkt der Begründung des Urteils ist der Wahlrechtsgrundsatz der Wahlgleichheit, hier der Erfolgswertgleichheit. Dazu führte das Gericht zwei Hauptargumente an:

- Die Erfolgschancengleichheit erlaube zwar, daß Stimmen nicht gewertet werden - z.B. als Folge der 5-Prozent-Sperrklausel oder überhaupt im Mehrheitswahlrecht -, ,nicht aber, dass einer Wahlstimme neben der Chance, zum beabsichtigten Erfolg beizutragen, auch die Gefahr, dem eigenen Wahlziel zu schaden, innewohnt." $" 88$

- Dieser Effekt des negativen Stimmgewichts hänge von verschiedenen Faktoren ab, die ,nicht vorhersehbar oder planbar sind und von dem einzelnen Wähler kaum beeinflußt werden können. Damit handelt es sich in aller Regel um eine zufällige Folge des Wählerverhaltens““ ${ }^{89}$

Dazu kommen zwei Nebenargumente:

- Der Effekt des negativen Stimmgewichts entstehe „nicht nur in sehr seltenen Ausnahmefällen“, die vernachlässigt werden könnten..$^{90}$ Das Gericht brachte dazu selbst ein Beispiel aus Hamburg: Wären dort „,ür die SPD etwa 19.500 Zweitstimmen weniger abgegeben worden, so hätte diese Partei im Ergebnis einen Sitz mehr im Deutschen Bundestag beanspruchen können. Damit haben 19.500 Wäh-

85 BVerfGE 121, 266 (267).

86 A.a.O., 277.

87 Vgl. H. Meyer, Lösungsmöglichkeiten nach dem Wahlrechtsurteil des BVerfG vom 3. Juli 2008, DVB1. 2009, 137; D. Lübbert, Negative Stimmgewichte und die Reform des Bundestags-Wahlrechts, Deutscher Bundestag: Info-Brief WD 8 - 3000 - 020/09 (abgeschlossen 18.3.2009); M. König, Paradoxie des negativen Stimmgewichts, ZG 24 (2009), 177 (189 ff.).

88 BVerfGE 121, 266 (301)

89 A.a.O., 299, vgl. 305.

90 A.a.O., 301. 
ler der SPD in Hamburg dieser Partei durch ihre Stimme geschadet. Die Stimmen dieser Wähler haben sich für die Mandatsverteilung zu Lasten derjenigen Partei ausgewirkt, für die die Stimme abgegeben wurde.“91

- Diese Beeinträchtigung der Gleichheit der Wahl durch das negative Stimmgewicht könne „,nicht durch ,zwingende ' Gründe gerechtfertigt werden“992 (erörtert im Anschluß an den Belangen des föderalen Proporzes).

Im Ergebnis beeinträchtige der Effekt des negativen Stimmgewichts „die Stimmengleichheit bei der Wahl zum Deutschen Bundestag in eklatanter Weise. Die Erfolgswertgleichheit fordert, dass der Erfolgswert jeder Stimme, für welche Partei sie auch immer abgegeben wurde, gleich ist. Dies bedeutet auch, dass sie für die Partei, für die sie abgegeben wurde, positive Wirkung entfalten können muss. Ein Wahlsystem, das darauf ausgelegt ist oder doch jedenfalls in typischen Konstellationen zuläßt, dass ein Zuwachs an Stimmen zu Mandatsverlusten führt oder dass für den Wahlvorschlag einer Partei insgesamt mehr Mandate erzielt werden, wenn auf ihn selbst weniger oder auf einen konkurrierenden Vorschlag mehr Stimmen entfallen, führt zu willkürlichen Ergebnissen und läßt den demokratischen Wettbewerb um Zustimmung bei den Wahlberechtigten widersinnig erscheinen. “93 „Ein Berechnungsverfahren, das dazu führt, dass eine Wählerstimme für eine Partei eine Wirkung gegen diese Partei hat, widerspricht aber Sinn und Zweck einer demokratischen Wahl." 94 „Der Eingriff in die Gleichheit der Wahl durch den Effekt des negativen Stimmgewichts ist von hoher Intensität. Er führt nicht nur dazu, dass Wählerstimmen bei der Zuteilung der Mandate unterschiedlich gewichtet werden, sondern bewirkt, dass der Wählerwille in sein Gegenteil verkehrt wird, indem sich eine Stimmabgabe zu Lasten der gewählten Partei auswirkt. Die Wirkung des negativen Stimmgewichts ist willkürlich. “95

Dem Bundesverfassungsgericht zufolge verletzt die einschlägige Regelung auch die verfassungsrechtlich verbürgte Unmittelbarkeit der Wahl.

Der Wähler könne ,nicht erkennen, ob sich seine Stimme stets für die zu wählende Partei und deren Wahlbewerber positiv auswirkt, oder ob er durch seine Stimme den Mißerfolg eines Kandidaten seiner eigenen Partei verursacht. [...] Die vom Wähler beabsichtigte Stärkung einer politischen Kraft kann diese aufgrund des Effekts des negativen Stimmgewichts auch schwächen. Gesetzliche Regelungen, die derartige Unwägbarkeiten nicht nur in seltenen und unvermeidbaren Ausnahmefällen hervorrufen, sind mit dem Grundsatz der Unmittelbarkeit der Wahl nicht zu vereinbaren." $" 96$

Der Bevollmächtigte der Beschwerdeführer pointierte: „Um den Effekt zu erreichen, dass eine Stimme für eine Partei wie eine Stimme gegen die Partei wirkt, muss

91 A.a.O., 311; ein weiteres Beispiel aus Thüringen bringt König, Paradoxie (Fn. 87), 181.

92 BVerfGE 121, 266 (302).

93 A.a.O., 299.

94 A.a.O., 300.

95 A.a.O., 304.

96 A.a.O., 308. 
man in Bananenrepubliken zur Wahlfälschung schreiten, wir schaffen das durch Parlamentsgesetz! ‘97

Jedenfalls im Ergebnis und was die Wahlrechtsgleichheit anbelangt, wurde dieses Urteil, soweit ersichtlich, allgemein gebilligt. ${ }^{98}$

\section{2. Übertragbarkeit dieses Maßstabs auf das Beteiligungsquorum?}

Abstrakt gesprochen, gilt natürlich auch für das Regelwerk eines Volksentscheids, daß es „grundsätzlich frei von willkürlichen und widersinnigen Effekten sein“ muß. ${ }^{99}$ Auch bei der direkten Demokratie kann man verlangen, daß das Reglement keine „unsinnigen Ergebnisse“ 100 „,absurden Wirkungen“101 oder „widersinnige Wirkungen" 102 produziert bzw. zuläßt. Aber auch bei der konkreten Prüfung anhand der Begründung des Wahlrechtsurteils spricht alles für die Übertragbarkeit:

- Gewiß müssen die Sachgegner bei einem Volksentscheid hinnehmen, daß ihre „Nein“-Stimme gegebenenfalls keine Wirkung hat, weil sich an den Urnen eine „Ja“-Mehrheit ergibt. Insofern folgt ein Volksentscheid der Logik des Mehrheitswahlrechts. Aber es geht zu weit, wenn ihr bekundeter politischer Wille, einen Gesetzentwurf abzulehnen, ins Gegenteil verkehrt wird, weil sie mit dieser Bekundung die Annahme der Vorlage bewirken.

- Diese Wirkung des Beteiligungsquorums ist in concreto nicht vorhersehbar. Obwohl der Abstimmende glaubt, mit seiner „Nein“-Stimme zur Ablehnung des begehrten Entwurfs beizutragen, kann das Beteiligungsquorum dazu führen, daß er genau das Gegenteil bewirkt. ${ }^{103}$

- Solche Situationen kommen nur deshalb selten vor, weil überhaupt in Deutschland vergleichsweise wenige Volksentscheide stattfinden und es ja nur drei Regelwerke mit einem Beteiligungsquorum gibt. Aber wenn man sich eine rege Praxis wie in der Schweiz, den US-Bundesstaaten oder auch in Italien vorstellt, ist kein Zweifel, daß sich dieser Effekt des Beteiligungsquorums durchaus öfter einstellen wird.

97 Meyer, Lösungsmöglichkeiten (Fn. 87), 146 (Hervorhebungen i.O.).

98 Vgl.H.H. v. Arnim, Verfassungswidrigkeit des Bundeswahlgesetzes aufgrund des ,, negativen Stimmgewichts“. Anmerkungen zum Urteil des Bundesverfassungsgerichts vom 3. Juli 2008, RuP 44 (2008), 136; G. Roth, Negatives Stimmgewicht und Legitimationsdefizite des Parlaments, NVwZ 2008, 1199; D. Nohlen, Erfolgswertgleichheit als fixe Idee oder: Zurück zu Weimar? Zum Urteil des Bundesverfassungsgerichts über das Bundeswahlgesetz vom 3. Juli 2008, ZParl 40 (2009), 179 (mit Vorbehalten hinsichtlich der vorgeworfenen Verletzung des Grundsatzes der Unmittelbarkeit des Wahl, 190 ff.); König, Paradoxie (Fn. 87), 195.

99 BVerfGE 121, 266 (300).

100 v. Arnim, Verfassungswidrigkeit (Fn. 98), 137.

101 Roth, Stimmgewicht (Fn. 98), 1200.

102 Nohlen, Erfolgswertgleichheit (Fn. 98), 192.

103 Vgl. BVerfGE 121, 266 (299). 
- Es gibt keinen Rechtfertigungsgrund für ein Beteiligungsquorum, der solche Effekte hinzunehmen zwänge. Auf jeden Fall könnte man auf ein Zustimmungsquorum von halber Höhe umstellen, womit die Gefahr des inversen Erfolgswerts gebannt wäre.

\section{Der Umgang mit dem Problem}

Im Prinzip ist die Quorenproblematik bekannt, wenn auch gewiß nicht in allen Einzelheiten und Beispielsfällen. Schon nach dem Bürgerentscheid zur Auflösung des Münchner Stadtrats vom 12. Dezember 1920 wurde die Boykott-Versuchung richtig analysiert, ${ }^{104}$ erst recht nach den beiden reichsweiten Volksentscheiden von 1926 und 1929. ${ }^{105}$ Gleichwohl hat die Politik daraus nach dem Zweiten Weltkrieg kaum eine Lehre gezogen. ${ }^{106}$ Auch bei den jüngsten Neu-Einführungen von Beteiligungsquoren in Rheinland-Pfalz 2000, Nordrhein-Westfalen 2002 und Berlin 2005 wirkte die Politik insoweit eigenartig indolent. Entschuldigend mag man hier auf unzulängliche Beratung verweisen. So kann etwa der Enquete-Kommission „Verfassungsreform“ in Rheinland-Pfalz durchaus ein mangelndes Problembewußtsein attestiert werden. ${ }^{107}$ Auch fällt auf, daß die Kommentare und die sonstige Literatur das Beteiligungsquorum kaum problematisieren. ${ }^{108}$ Gewiß, gerade die nordrheinwestfälische Hürde wird ,,in der Praxis nur schwer zu erreichen sein“; ${ }^{109}$ aber damit sind die spezifischen Risiken dieser Zusatzbedingung, die hier erörtert wurden, keineswegs erfaßt. Selbst bei Wissenschaftlern, die sich intensiv mit direkter Demokratie befaßt haben, kann man an dieser Stelle auf einen „blinden Fleck“ treffen, ${ }^{110}$ und in der Politik erscheint manchmal das Verdikt „naiv“ unumgänglich. ${ }^{111}$

104 Vgl. Schmidt, Gemeindedemokratie (Fn. 50), S. 57 f.

105 Vgl. C. Tannert, Die Fehlgestalt des Volksentscheids. Gesetzesvorschlag zur Änderung der Art. 75 und 76 Abs. 1 Satz 4 der Reichsverfassung, 1929; ferner Jung, Volksgesetzgebung (Fn. 17), S. 1048 ff.; Schwieger, Volksgesetzgebung (Fn. 21), S. 169-179; Wiegand, Direktdemokratische Elemente (Fn. 12), S. 103-119.

106 Vgl. Jung, Volksgesetzgebung (Fn. 17), S. 1050 ff.; ders., Das Quorenproblem beim Volksentscheid. Legitimität und Effizienz beim Abschluß des Verfahrens der Volksgesetzgebung, ZPol 9 (1999), 863 (867 f.).

107 Vgl. den Bericht der Enquete-Kommission „Verfassungsreform“, LT Drs. 12/5555 v. 27.10.1994, S. $23 \mathrm{f}$.

108 Vgl. D. Franke, in: C. Grimm/P. Caesar (Hrsg.), Verfassung für Rheinland-Pfalz. Kommentar, 2001, Art. 109 Rdnr. 39. - P. Paulus, Direkte Demokratie in Rheinland-Pfalz, in: Kost, Direkte Demokratie (Fn. 5), S. 204 (210), hingegen spricht die Problematik eines Beteiligungsquorums an.

109 So T. Mann, in: W. Löwer/P.J. Tettinger (Hrsg.), Kommentar zur Verfassung des Landes Nordrhein-Westfalen, 2002, Art. 69 Rdnr. 17. - A. Kost, Direkte Demokratie in NordrheinWestfalen, in: ders., Direkte Demokratie (Fn. 5), S. 183 (191 f.), problematisiert die Entscheidung für ein Beteiligungsquorum nicht.

110 B.A. Weixner, Direkte Demokratie in den Bundesländern. Verfassungsrechtlicher und empirischer Befund aus politikwissenschaftlicher Sicht, 2002, S. 162, 178, 276, schrieb z.B. so arglos über das Beteiligungsquorum, als ob dessen einzige Eigenschaft wäre, daß sein Satz das Doppelte eines entsprechenden Zustimmungsquorums betrüge. In ihrem „Versuch einer ide- 
Doch der Hauptgrund dürfte der folgende politikimmanente sein: Nach wie vor wird die direkte Demokratie in Deutschland von den Parteien wenig „geliebt“ und im Grund nur gefordert, wenn sie in der Opposition sind. Dann aber gilt die politische Regel wie zur Weimarer Zeit: Die Unbill, daß ein direktdemokratisches Projekt von der Gegenseite gegebenenfalls durch Boykott zunichte gemacht werden kann, wird mehr als kompensiert durch die Aussicht, daß, wenn man selbst an der Regierung ist und die andere Seite dann auf direktdemokratischem Wege opponiert, mit den Quoren eine „Notbremse“ zur Verfügung steht, um solche Vorstöße abzuwehren. Kurz: Die Volksbegehren der anderen zu hintertreiben erscheint wichtiger, als mit den eigenen Volksbegehren Erfolg zu haben.

\section{E. Verfassungspolitischer Lösungsvorschlag}

Die „große Lösung“ wäre, quorenfreie Volks- bzw. Bürgerentscheide vorzusehen. Die Referenzländer mit diesem Regelwerk - die Schweiz und die US-Bundesstaaten, aber auch Bayern - zeigen, daß die hierzulande üblichen abstrakten Bedenken (,dann geht nur einer hin“) bloß schlechte Theorie und praktisch irrelevant sind. Als „kleine Lösung“" sollten die vorhandenen Beteiligungsquoren umgestellt werden auf ein Zustimmungsquorum von halber Höhe. Vor allem aber sollte man sich bei den Reformentwürfen für Volksentscheide auf Bundesebene von dem Instrument des Beteiligungsquorums verabschieden.

altypischen Volksgesetzgebung“ führte sie dazu aus: „Im Volksentscheid kann ein Beteiligungsquorum von 25 Prozent der Stimmberechtigten festgelegt werden, das zugleich erfüllbar ist und die Akzeptanz im Land stärkt.“ (S. 178). Boykott, inverser Erfolgswert - anscheinend unbekannt.

111 So begründete die Fraktion Bündnis 90/Die Grünen im Hessischen Landtag ihren erwähnten Vorschlag eines 50prozentigen Beteiligungsquorums bei der verfassungsändernden Volksgesetzgebung unbefangen wie folgt: „Nur dann werden sich ausreichend Stimmberechtigte an der Volksabstimmung beteiligen." HessLT Drs. 17/481 v. 13.8.2008, S. 4. - Weimar läßt grüßen! 